\title{
Essential fatty acid status in neonates after fish-oil supplementation during late pregnancy
}

\author{
BY ADRIANA C. VAN HOUWELINGEN'², JANNY DALBY SØRENSEN², \\ GERARD HORNSTRA ${ }^{1}$, MARIANNE M. G. SIMONIS ${ }^{1}$, JANE BORIS², \\ SJURDUR F, OLSEN ${ }^{3}$ AND NIELS J. SECHER ${ }^{2}$ \\ ${ }^{1}$ Department of Human Biology, Limburg University, Maastricht, The Netherlands \\ ${ }^{2}$ Department of Gynecology and Obstetrics, University of Aarhus, Denmark \\ ${ }^{3}$ Institute of Epidemiology and Social Medicine, University of Aarhus, Denmark
}

(Received 18 July 1994 -Revised 24 January 1995-Accepted 2 March 1995)

\begin{abstract}
Healthy pregnant women ( $n$ 23) were supplemented with fish-oil capsules $(2 \cdot 7 \mathrm{~g} n-3$ polyunsaturated fatty acids/d) from the 30th week of gestation until delivery. Subjects in a control group were either supplemented with olive-oil capsules $(4 \mathrm{~g} / \mathrm{d}, n$ 6) or received no supplementation $(n 10)$. Fatty acid compositions of the phospholipids isolated from umbilical plasma and umbilical arterial and venous vessel walls were determined. Fatty acid compositions of maternal venous plasma phospholipids were determined as well. Maternal plasma phospholipids of the fish-oil-supplemented group contained more $n-3$ fatty acids and less $n-6$ fatty acids. Moreover, the amounts of the essential fatty acid deficiency markers Mead acid (20:3n-9) and Osbond acid (22:5n-6) were significantly lower. The extra amount of $n-3$ fatty acids consumed by the mothers resulted in higher contents of $n-3$ fatty acids, and of docosahexaenoic acid (22:6n-3) in particular, in the phospholipids of umbilical plasma and vessel walls. It is, indeed, possible to interfere with the docosahexaenoic acid status at birth: children born to mothers supplemented with fish oil in the last trimester of pregnancy start with a better docosahexaenoic acid status at birth, which may be beneficial to neonatal neurodevelopment.
\end{abstract}

Fatty acids: Phospholipids: Neonates: Fish oil

Based on fatty acid profiles of cord vessels and adult blood vessels respectively, we obtained strong indications that the biochemical essential fatty acid (EFA) status of neonates, born after normal pregnancy, is not optimal compared with that of adults (Hornstra et al. 1989). For its EFA, the developing fetus depends completely on the maternal supply. The fetus seems to have a high requirement of docosahexaenoic acid (DHA; 22:6n-3) (Hornstra et al. 1989; Al et al. 1990), which is of essential importance in fetal brain development (Crawford et al. 1976; Clandinin et al. 1980). A high intake of long-chain $n-3$ fatty acids in pregnancy has been suggested to prolong gestation (Olsen et al. 1986, 1992). In addition, the occurrence of obstetric complications such as pregnancy-induced hypertension (Andersen et al. 1989; Secher \& Olsen, 1990; Baker \& Broughton-Pipkin, 1991; Popeski et al. 1991) or intra-uterine growth retardation (Vilbergson et al. 1991) may decrease after higher intake of $n-3$ long chain polyenes (LCP) in pregnancy.

In the present study we investigated the feasibility of improving the fetal $n-3$ status by maternal fish-oil supplementation during the last trimester of pregnancy. To assess the fetal EFA status we analysed the fatty acid composition of phospholipids isolated from umbilical plasma and arterial and venous vessel walls of neonates at delivery. Nutrients from the mother are transported to the fetus through the umbilical vein, and blood flows 
back from the fetus to the mother via the umbilical arteries. Since the umbilical vessel walls do not have a vasa vasorum to obtain their nutrient supply, they obtain their nutrients directly from the blood flowing through them. Therefore, the EFA composition of umbilical venous walls is considered to be a long-term reflection of the EFA supply from mother to fetus, whereas the fatty acid composition of the arterial vessel walls is likely to reflect the EFA status of the 'down-stream' tissue of the developing fetus. In addition, the effect of fish-oil supplementation on the maternal EFA status during pregnancy (30th and 37 th weeks of gestation) and at delivery was studied.

\section{SUBJECTS, MATERIALS AND METHODS}

Healthy pregnant women were supplemented from the 30 th week of gestation until delivery. The present biochemical study is a substudy of a larger population-based trial of fish oil in pregnancy described elsewhere (Olsen et al. 1992). The volunteers were allocated at random to two groups: (1) the experimental group $(n 23)$ received four $1 \mathrm{~g}$ capsules of fish oil/d (Pikasol: $32 \mathrm{~g}$ eicosapentaenoic acid (EPA; 20:5n-3)/100 $\mathrm{g}$ fish oil and $23 \mathrm{~g}$ DHA (22:6n-3)/100 $\mathrm{g}$ fish oil, with $2 \mathrm{mg}$ tocopherol/ml as an antioxidant). This corresponds to $2.7 \mathrm{~g} n-3$ fatty acids/d; (2) the control group ( $n$ 16) either received $4 \mathrm{~g} / \mathrm{d}$ encapsuled olive oil $(72 \%$ oleic acid $(18: 1 n-9)$ and $12 \%$ linoleic acid $(18: 2 n-6), n 6)$ or received no supplementation $(n 10)$. Patients with a history of placenta abruption in a previous pregnancy or a serious bleeding episode in the present pregnancy were excluded. Women who regularly used prostaglandin inhibitors were also ineligible. Other exclusion criteria were multiple pregnancy, allergy to fish and regular intake of fish oil.

Fatty acid compositions of phospholipids were determined in maternal venous EDTAplasma collected in the 30th and 37th weeks of gestation and at delivery, and in venous umbilical plasma as well. In addition, a piece $(50 \mathrm{~mm})$ of the umbilical cord was collected immediately after birth, rinsed with saline and stored at $-80^{\circ}$ until analysed. The arterial and venous vessel walls were dissected free from adjacent tissue, homogenized, and freeze dried.

Total lipid extraction was performed as described by Bligh \& Dyer (1959) on $100 \mu 1$ plasma and $125 \mu \mathrm{g}$ dry tissue. L- $\alpha$-Dinonadecanoyl lecithin (PC 19:0) was used as an internal standard to quantify the fatty acids.

Phospholipid fractions were isolated by solid-phase extraction according to the method of Kaluzny et al. (1985), after which they were hydrolysed, and their fatty acids methylated with $\mathrm{BF}_{3}$ in methanol (Morissen \& Smith, 1964). Fatty acid compositions were then determined by GLC using a capillary column (CP SIL 88 for the vessel walls, and CP SIL 5 for the plasma samples; Chrompack ${ }^{\mathbb{B}}$, Middelburg, The Netherlands). The results were expressed as $\mu \mathrm{g}$ fatty acid $/ \mathrm{ml}$ plasma or $\mu \mathrm{g} / \mathrm{g}$ dry tissue (absolute amount) and as $\mathrm{g} / 100 \mathrm{~g}$ total fatty acids (relative amount).

\section{Statistics}

The effects of fish-oil consumption were compared with the combined control group (olive oil and no supplement) because the amounts of linoleic acid $(18: 2 n-6)$ and oleic acid $(18: 1 n-9)$ given in the olive-oil supplement were very small ( $<3 \%$ and $<10 \%$ respectively) compared with the average intake by Danish women (Olsen et al. 1992). Linear regression was used to investigate relations between maternal and neonatal values. Differences between the experimental and control groups were evaluated with Student's $t$ tests (twosided). $P$ values $<0.05$ were considered significant. The major EFA will be reported, as well as the sum of the $n-6$ LCP (which includes all $n-6$ fatty acids except linoleic acid), the sum of the $n-3$ fatty acids, the sum of the saturated fatty acids and finally the sum of the $n-7$ and 
Table 1. Clinical characteristics of the subjects

\begin{tabular}{|c|c|c|c|c|c|c|}
\hline & \multicolumn{3}{|c|}{ Fish oil ( $n$ 23) } & \multicolumn{3}{|c|}{ Control ( $n$ 16) } \\
\hline & Mean & SE & Range & Mean & SE & Range \\
\hline Age (years) & $28 \cdot 0$ & 1.02 & 21-39 & $28 \cdot 0$ & 0.584 & $22-31$ \\
\hline Gestational age (d) & 285 & $1 \cdot 5$ & $271-299$ & 285 & 1.9 & $268-296$ \\
\hline Gestational age (week.d) & $40 \cdot 5$ & 0.2 & $38 \cdot 5-42 \cdot 5$ & $40 \cdot 5$ & $0 \cdot 2$ & $38 \cdot 2-42 \cdot 2$ \\
\hline Birth weight (g) & 3716 & 69 & $2945-4350$ & 3547 & 87 & $2880-4350$ \\
\hline Length at birth (mm) & 524 & 2.6 & $490-570$ & 518 & 3.7 & $490-540$ \\
\hline Head circumference (mm) & 347 & $3 \cdot 7$ & $320-370$ & 351 & $4 \cdot 2$ & $320-370$ \\
\hline
\end{tabular}

Table 2. Fatty acid composition of venous umbilical plasma phospholipids in neonates of women consuming a fish-oil supplement and in controls*

(Mean values with their standard errors)

\begin{tabular}{|c|c|c|c|c|c|}
\hline \multirow[b]{2}{*}{ Fatty acid } & \multicolumn{2}{|c|}{ Fish oil ( $n$ 18) } & \multicolumn{2}{|c|}{ Control ( $n$ 15) } & \multirow[b]{2}{*}{$P$ value $\dagger$} \\
\hline & Mean & $\mathrm{SE}$ & Mean & SE & \\
\hline Total (mg/l) & 698.8 & $33 \cdot 4$ & $727 \cdot 9$ & $23 \cdot 1$ & NS \\
\hline \multicolumn{6}{|l|}{$\mathrm{g} / 100 \mathrm{~g}$ total fatty acids } \\
\hline $20: 5 n-3$ & 1.40 & $0 \cdot 17$ & $0 \cdot 38$ & $0 \cdot 04$ & $<0.0001$ \\
\hline $22: 6 n-3$ & 7.85 & $0-41$ & 6.74 & 0.30 & 0.0428 \\
\hline $18: 2 n-6$ & $7 \cdot 11$ & $0 \cdot 30$ & 6.40 & 0.25 & NS \\
\hline $20: 4 n-6$ & 14.96 & 0.48 & $17 \cdot 07$ & 0.28 & 0.0010 \\
\hline $22: 5 n-6$ & 0.30 & 0.02 & 0.41 & 0.06 & $<0.0001$ \\
\hline $20: 3 n-9$ & 0.32 & 0.03 & 0.44 & 0.04 & NS \\
\hline Sum of $n-3$ & $10 \cdot 33$ & 0.55 & $7 \cdot 78$ & 0.34 & 0.0007 \\
\hline Sum of $n-6$ LCP & 21.48 & 0.45 & $24 \cdot 34$ & 0.36 & $<0.0001$ \\
\hline Sum of $n-7+n-9$ & $12 \cdot 44$ & 0.35 & $12 \cdot 78$ & $0 \cdot 27$ & NS \\
\hline Sum of saturates & 45.98 & 0.14 & $45 \cdot 51$ & 0.22 & NS \\
\hline $18: 2 n-6 / 20: 4 n-6$ & 0.486 & 0.03 & $0 \cdot 377$ & 0.02 & 0.0036 \\
\hline
\end{tabular}

LCP, long-chain polyenes.

* For details of procedures, see p. 724.

$\dagger$ Fish-oil group $v$. combined control group (Student's $t$ test).

n-9 fatty acids together. Full data detailing all fatty acids separately, are available on request.

\section{RESULTS}

Random allocation generated groups that were similar at baseline with respect to available maternal characteristics as well as to the levels of variables characterizing the fetal and maternal EFA status (Table 1). Some samples were not collected at the hospital and we lost some samples during analysis. There were no significant differences in total amounts of fatty acids between the study groups; therefore, only relative values of the individual fatty acids $(\mathrm{g} / 100 \mathrm{~g})$ are given.

\section{Umbilical plasma}

The relative values of the fatty acid composition of venous umbilical plasma phospholipids are reported in Table 2 . The levels of all $n-3$ fatty acids were significantly higher in the fishoil group compared with the control group. This was associated with significant reductions 
Table 3. Fatty acid composition of the umbilical vessel wall phospholipids from neonates of women supplemented with fish oil, and controls*

(Mean values with their standard errors)

\begin{tabular}{|c|c|c|c|c|c|}
\hline \multirow[b]{2}{*}{ Fatty acid } & \multicolumn{2}{|c|}{ Fish oil ( $n$ 23) } & \multicolumn{2}{|c|}{ Control ( $n$ 16) } & \multirow[b]{2}{*}{$P$ value $\dagger$} \\
\hline & Mean & $\mathrm{SE}$ & Mean & $\mathrm{SE}$ & \\
\hline \multicolumn{6}{|l|}{ Artery } \\
\hline Total $(\mathrm{mg} / \mathrm{kg})$ & 15401 & 953 & 13751 & 743 & NS \\
\hline \multicolumn{6}{|l|}{$\mathrm{g} / 100 \mathrm{~g}$ total fatty acids } \\
\hline $20: 5 n-3$ & 0.09 & 0.02 & 0.03 & 0.01 & 0.01 \\
\hline $22: 6 n-3$ & 6.37 & $0 \cdot 18$ & 5.48 & 0.17 & 0.0013 \\
\hline $18: 2 n-6$ & $1 \cdot 15$ & 0.05 & 1.04 & 0.05 & NS \\
\hline $20: 4 n-6$ & 11.83 & 0.32 & $12 \cdot 35$ & 0.50 & NS \\
\hline $22: 5 n-6$ & 2.34 & 0.08 & 2.68 & $0 \cdot 15$ & 0.0311 \\
\hline $20: 3 n-9$ & $2 \cdot 61$ & $0 \cdot 11$ & 2.53 & 0.20 & NS \\
\hline Sum of $n-3$ & 7.00 & 0.21 & 5.85 & $0 \cdot 16$ & 0.0003 \\
\hline Sum of $n-6$ LCP & 17.95 & 0.40 & $19 \cdot 21$ & 0.71 & NS \\
\hline Sum of $n-7+n-9$ & $22 \cdot 20$ & 0.55 & 21.91 & 0.86 & NS \\
\hline Sum of saturates & $41 \cdot 71$ & 0.39 & $41-92$ & 0.60 & NS \\
\hline $18: 2 n-6 / 20: 4 n-6$ & $0 \cdot 10$ & 0.004 & 0.09 & 0.004 & 0.0047 \\
\hline \multicolumn{6}{|l|}{ Vein } \\
\hline Total $(\mathrm{mg} / \mathrm{kg})$ & 16918 & 552 & 16560 & 768 & NS \\
\hline \multicolumn{6}{|l|}{$\mathrm{g} / 100 \mathrm{~g}$ total fatty acids } \\
\hline $20: 5 n-3$ & $0 \cdot 10$ & 0.02 & 0.04 & 0.01 & 0.0086 \\
\hline $22: 6 n-3$ & 6.59 & $0 \cdot 16$ & $5 \cdot 62$ & $0 \cdot 22$ & 0.0008 \\
\hline $18: 2 n-6$ & 1.67 & 0.07 & 1.60 & $0 \cdot 10$ & NS \\
\hline $20: 4 n-6$ & $15 \cdot 16$ & 0.29 & 15.84 & 0.41 & NS \\
\hline $22: 5 n-6$ & 1.85 & $0 \cdot 10$ & $2 \cdot 25$ & $0 \cdot 14$ & 0.0167 \\
\hline $20: 3 n-9$ & 0.58 & 0.06 & 0.63 & $0 \cdot 10$ & NS \\
\hline Sum of $n-3$ & $7 \cdot 36$ & 0.20 & 6.02 & $0 \cdot 26$ & 0.0002 \\
\hline Sum of $n-6 \mathrm{LCP}$ & $23 \cdot 42$ & 0.38 & $24 \cdot 60$ & 0.57 & NS \\
\hline Sum of $n-7+n-9$ & $15 \cdot 61$ & $0-38$ & 15.43 & 0.41 & NS \\
\hline Sum of saturates & $42 \cdot 60$ & 0.43 & $42 \cdot 96$ & 0.70 & NS \\
\hline $18: 2 n-6 / 20: 4 n-6$ & 0.11 & 0.005 & $0 \cdot 10$ & 0.007 & NS \\
\hline
\end{tabular}

LCP, long-chain polyenes.

* For details of procedures, see p. 724.

$\dagger$ Fish-oil group v. combined control group (Student's $t$ test).

in arachidonic acid (20:4n-6) and Osbond acid (22:5n-6), resulting in significantly lower levels of $n-6$ LCP. There were no significant differences between the groups in the levels of linoleic acid (18:2n-6) and Mead acid (20:3n-9).

\section{Umbilical vessel walls}

The total amount of fatty acids in the phospholipid fraction of the arterial walls was on average $10 \%$ lower than in the venous wall of the umbilical cords (Table 3 ). In the arterial as well as in the venous vessel walls, significantly more of the $n-3$ fatty acids EPA and DHA were present in the fish-oil group than in the control group. This was associated with a significant reduction in the level of Osbond acid. Neither in the arterial nor in the venous vessel walls were significant differences between the study groups observed for the other $n$ 6 fatty acids. In addition, no differences were observed for Mead acid and no influence of the fish-oil supplement could be observed on the difference between arteries and veins (results not shown). 
Table 4. Changes in the fatty acid composition of maternal plasma phospholipids in pregnant women consuming a fish-oil supplement, and in controls*

(Mean values with their standard errors)

\begin{tabular}{|c|c|c|c|c|c|c|c|}
\hline \multirow[b]{3}{*}{ Fatty acid } & \multirow{2}{*}{\multicolumn{2}{|c|}{$\begin{array}{c}\text { Value at } \\
\text { week } 30(n 36)\end{array}$}} & \multicolumn{4}{|c|}{ Change at week 37} & \multirow[b]{3}{*}{$P$ value $\dagger$} \\
\hline & & & \multicolumn{2}{|c|}{ Fish oil ( $n$ 20) } & \multicolumn{2}{|c|}{ Control (n 16) } & \\
\hline & Mean & $\mathrm{SE}$ & Mean & $\mathbf{S E}$ & Mean & SE & \\
\hline $\begin{array}{l}\text { Total }(\mu \mathrm{g} / \mathrm{ml}) \\
\mathrm{g} / 100 \mathrm{~g} \text { total fatty acids }\end{array}$ & 1599 & $37 \cdot 0$ & $+181 \cdot 0$ & $68 \cdot 0$ & $+175 \cdot 5$ & $52 \cdot 5$ & NS \\
\hline $20: 5 n-3$ & 0.64 & 0.05 & $+2 \cdot 19$ & 0.22 & $+0 \cdot 15$ & $0 \cdot 10$ & $<0.0001$ \\
\hline $22: 6 n-3$ & $4 \cdot 79$ & 0.15 & +2.66 & 0.29 & $+0-31$ & $0 \cdot 20$ & $<0.0001$ \\
\hline $18: 2 n-6$ & $20 \cdot 81$ & 0.28 & -2.89 & 0.41 & -0.74 & 0.53 & 0.0024 \\
\hline $20: 4 n-6$ & $7 \cdot 93$ & 0.19 & -0.78 & $0 \cdot 20$ & +0.08 & $0 \cdot 19$ & 0.0189 \\
\hline $22: 5 n-6$ & 0.36 & 0.02 & $-0 \cdot 20$ & 0.02 & +0.02 & 0.02 & $<0.0001$ \\
\hline $20: 3 n-9$ & $0 \cdot 16$ & 0.01 & -0.05 & 0.01 & $+0 \cdot 01$ & 0.01 & 0.0002 \\
\hline Sum of $n-3$ & 6.53 & 0.20 & $+5 \cdot 38$ & 0.54 & $+0 \cdot 48$ & 0.31 & $<0.0001$ \\
\hline Sum of $n-6$ LCP & $12 \cdot 60$ & 0.22 & $-2 \cdot 09$ & 0.29 & -0.02 & 0.22 & $<0.0001$ \\
\hline Sum of $n-7+n-9$ & $13 \cdot 01$ & $0 \cdot 17$ & -0.52 & 0.25 & +0.45 & 0.22 & 0.0070 \\
\hline Sum of saturates & $44 \cdot 32$ & $0 \cdot 13$ & $+0 \cdot 24$ & $0 \cdot 15$ & $-0 \cdot 12$ & 0.13 & NS \\
\hline $18: 2 n-6 / 20: 4 n-6$ & 0.436 & 0.02 & $-0 \cdot 13$ & 0.08 & -0.06 & $0 \cdot 12$ & NS \\
\hline
\end{tabular}

LCP, long-chain polyenes.

* For details of procedures, see p. 724.

$\dagger$ Fish-oil group $v$. combined control group (Student's $t$ test).

\section{Maternal plasma}

The fatty acid composition of maternal plasma phospholipids immediately before the start of the supplementation at the 30th week of pregnancy and the observed changes at week 37 of gestation are given in Table 4 . At week 30 there were no significant differences between the fish-oil group and the control group. Using multiple regression we were not able to find an influence of the amounts of fatty acids in maternal plasma at week 30 on the neonatal fatty acid values. In the fish-oil group the total amount of $n-3$ fatty acids increased by about $82 \%$. This was accompanied by a decrease in most $n-6$ fatty acids. The level of Mead acid (the deficiency marker for an overall EFA deficiency, see Holman, 1960) and Osbond acid (a specific marker for the shortage of DHA see Holman, 1977) decreased significantly in the fish-oil group. In the control group no changes were observed. For all fatty acids and fatty acid combinations reported the change in the fish-oil group differed significantly from that in the control group (the sum of the saturates excluded).

For the $n-3$ fatty acids highly significant correlations were found between the fatty acid values in maternal plasma phospholipids at week 37 (results not shown) as well as at delivery (Table 5), and the neonatal values in plasma as well as the vessel walls (Table 5). With respect to the $n-6$ fatty acids, correlations were mainly observed between the values in maternal and neonatal plasma. For Osbond acid the maternal values correlated with all neonatal values.

For the arterial vessel wall significant positive correlations were found between $22: 6 n-3$ and gestational age $(r 0.35, P=0.032)$, and a significant negative correlation was observed between $20: 3 n-9$ and gestational age $(r-0 \cdot 46 ; P=0 \cdot 004)$. 
Table 5. Correlations between maternal and neonatal fatty acids

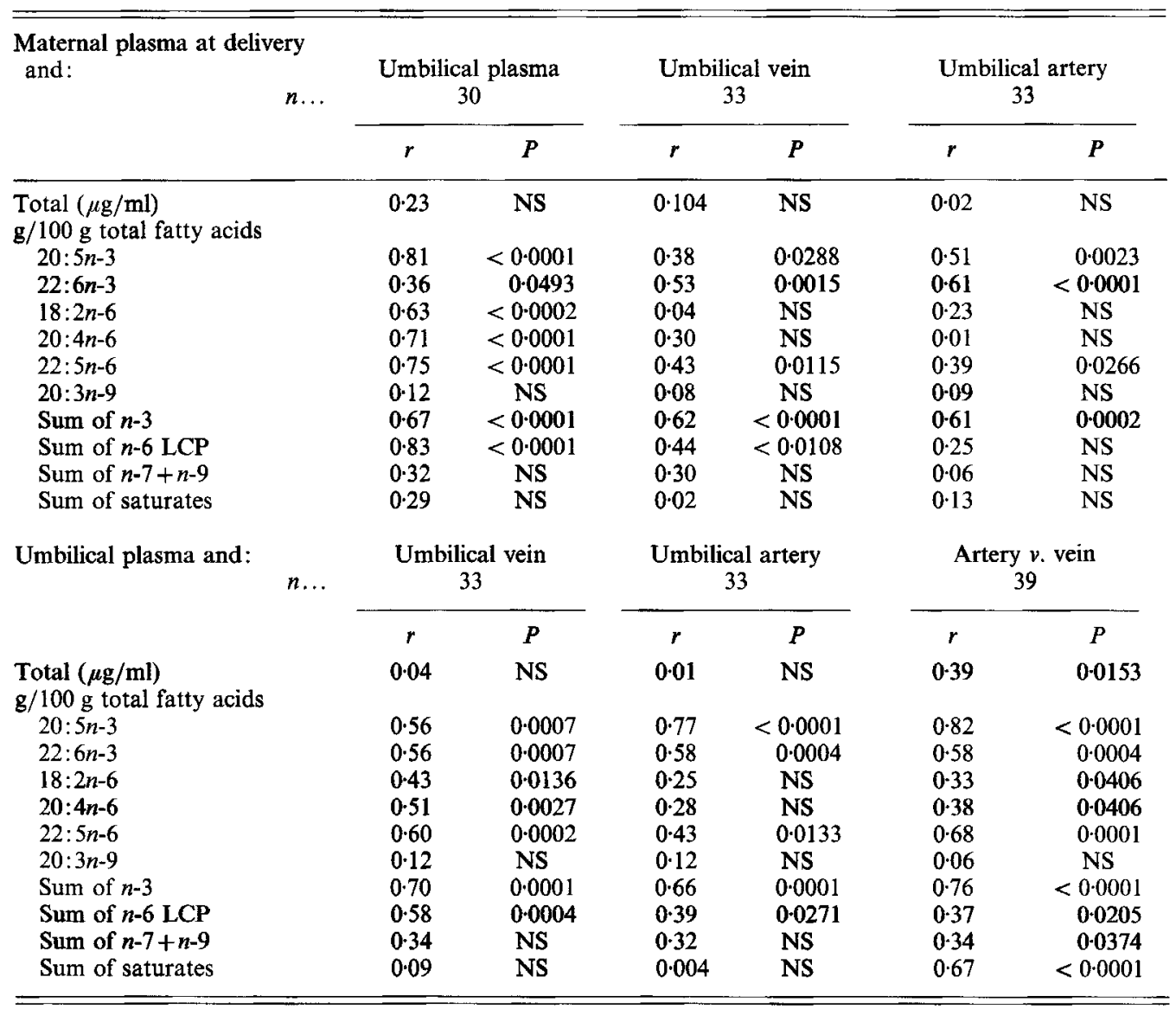

LCP, long-chain polyenes.

\section{DISCUSSION}

Fish-oil supplementation of pregnant women during the last trimester of pregnancy affected the $n-3$ status of their neonates. In the umbilical vessels, veins and arteries of the fish-oil group a significantly higher amount of DHA $(22: 6 n-3)$ was found compared with the control group. In the walls of both umbilical vessels this was associated with a significant reduction in the deficiency indicator of DHA, Osbond acid $(22: 5 n-6)$. These results demonstrate that fish-oil administration in the last trimester of pregnancy increases the fetal DHA content at birth. Since it has been shown that the $n-3$ status at birth has a rather long-term influence on the postnatal $n-3$ status (Foreman van Drongelen et al. 1995), the observed increase of the $n-3$ status in the newborn is likely to be of benefit also on the postnatal course of the $\boldsymbol{n - 3}$ status. This might be of importance, considering the postnatal intake of these important fatty acids is much smaller if the neonate is breast-fed, or is almost nil if the neonate is fed by artificial formulas. Since the neonatal conversion of precursor fatty acids to DHA probably occurs at an insufficient rate (Anderson et al. 1990), promotion of breast feeding and enrichment of infant formulas with DHA are indicated to improve the postnatal DHA status of newborns. The enhancement of $n-3$ fatty acids in 
early life is related to a better visual acuity (Uauy et al. 1992) and discriminative learning (Wainwright, 1992).

As a result of fish-oil supplementation, a decrease in the amount of $n-6$ fatty acid is to be expected (Houwelingen, 1988) and in maternal plasma this was indeed observed. In the venous vessel walls (reflecting the supply from the mother to the child) of the fish-oil group a tendency to a lower level of $n-6$ fatty acids was also observed, but significance was not reached in comparison with the control group. In contrast to the maternal values, the umbilical plasma phospholipid values of linoleic acid tended to be higher in the fish-oil group. Instead of this the arachidonic acid was decreased. This resulted in a significantly higher linoleic acid:arachidonic acid ratio in the fish-oil group (Table 2).

A relationship between arachidonic acid and growth has been observed (Koletzko \& Braun, 1991; Carlson et al. 1992). However, no relationship was found between the amount of arachidonic acid and birth weight in our study. Moreover, in a large population of Dutch term infants $(n 110)$ we were unable to find a correlation between the amount of arachidonic acid in umbilical plasma phospholipids and birth weight (M. D. M. Al, A. C. van Houwelingen and G. Hornstra, unpublished results). Furthermore, no influence of the supplementation could be observed on the arachidonic acid status of umbilical arteries and veins, which might give a longer-term reflection of the fetal fatty acid status of the last period of pregnancy than the umbilical plasma phospholipids.

In the neonatal material, fish-oil supplementation resulted in lower amounts of Osbond acid. Since Osbond acid is a deficiency marker for DHA (Holman, 1977), this clearly demonstrates the better DHA status of the neonates born to the fish-oil-supplemented mothers. Fish-oil supplementation did not significantly affect the average EFA status of the neonates as reflected by the insignificant effects on the neonatal amount of Mead acid.

The amounts of most fatty acids determined in the arteries correlated significantly with the amounts in the vein. However, the high levels of Mead acid in the artery did not correlate with the amount in the vein. Therefore, and because no influence of the $n-3$ supplementation on this fatty acid in the umbilical vessels was observed, it is questionable if the amount of Mead acid in this situation can be used as a deficiency marker. On the other hand, Mead acid is a deficiency marker for the overall EFA status, and because the $\Sigma n-3+\Sigma n-6$ fatty acids changed in opposite directions and the calculated EFA status ( $\Sigma n$ $3+\Sigma n-6) /(\Sigma n-7+\Sigma n-9)$ did not change due to the $n-3$ supplementation, a change in Mead acid might not be expected. For maternal plasma phospholipids, however, the EFA status was better and the amount of Mead acid was significantly decreased in the fish-oil group.

A positive relationship was observed between gestational age and DHA in the arterial vessel walls $(r 0.35, P=0.032)$ and in the umbilical plasma $(r 0.42, P=0.018)$. This has been observed before in our Dutch populations (Hornstra, 1992). In addition, it is in agreement with the observation that the fish-oil-supplemented group in the larger study (Olsen et al. 1992) had, on average, a longer duration of pregnancy. Although the group selected for this 'biochemical' study did not, on average, have a longer gestation, the range of the gestational age in the fish-oil group was $3 \mathrm{~d}$ higher than in the control group.

In the fish-oil group the maternal plasma values showed the expected changes due to the fish-oil consumption (Table 4): an increase in $n-3$ and a decrease in $n-6$ fatty acids. These changes were maximal at week 37 of gestation. It has been reported that changes in fatty acid composition due to fish-oil supplementation result in significantly higher amounts of the EPA-derived eicosanoids thromboxane $A_{3}$ and prostaglandin $I_{3}$ (Sørensen et al. 1993). Since the thromboxane-prostacyclin balance may be involved in the aetiology of pregnancy-induced hypertension and pre-eclampsia (Walsh, 1985), the changes observed might be beneficial in the prevention or treatment of pre-eclampsia and intrauterine growth retardation. 
The results described in this paper clearly demonstrate that fish-oil supplementation of pregnant women from the 30 th week of pregnancy alters not only their own $n-3$ status, but that of their neonates as well. The enhancement of $n-3$ fatty acids in early life is likely to be of benefit (Uauy et al. 1992; Wainwright, 1992). Consequently, the higher neonatal 22:6n-3 status observed after fish-oil supplementation during pregnancy is possibly beneficial. Children from the fish-oil-supplemented women started with a better DHA status. Further evidence is necessary to conclude that the extra $n-3$ consumption during pregnancy is of functional value for mother and child.

\section{REFERENCES}

Al, M. D. M., Hornstra, G., van der Schouw, Y. T., Bulstra-Ramakers, M. T. E. W. \& Huisjes, J. (1990). Biochemical EFA status of mothers and their neonates after normal pregnancy. Early Human Development 24, 239-248.

Andersen, H. J., Andersen, L. F. \& Fuchs, A. R. (1989). Diet, pre-eclampsia and intra-uterine growth retardation. Lancet i, 1146.

Anderson, G. J., Connor, W. E. \& Corliss, J. D. (1990). Docosahexaenoic acid is the preferred dietary $n-3$ fatty acid for the development of the brain and retina. Pediatric Research 27, 89-97.

Baker, P. \& Broughton-Pipkin, F. (1991). Fish oil and pre-eclampsia (letter). British Journal of Obstetrics and Gynaecology 98, 499-500.

Bligh, E. G. \& Dyer, W. J. (1959). A rapid method for total lipid extraction and purification. Canadian Journal of Biochemistry and Physiology 37, 911-917.

Carlson, S. E., Cooke, R. J., Werkman, S. H. \& Tolley, E. A. (1992). First year growth of preterm infants fed standard compared to marine oil supplemented formula. Lipids 27, 901-907.

Clandinin, M. T., Chappell, J. E., Leong, S., Heim, T., Sawyer, P. R. \& Chance, G. W. (1980). Intrauterine fatty acid accretion rates in human brain: implications for fatty acid requirements. Early Human Development 4 , 121-129.

Crawford, M. A., Hassam, A. G. \& Williams, G. (1976). Essential fatty acids and fetal brain growth. Lancet 1, 452-453.

Foreman van Drongelen, M. M. H. P., Houwelingen, A. C. v., Kester, A. D. M., de Jong, A. E. P., Blanco, C. E., Hasaart, T. H. M. \& Hornstra, G. (1995). Long-chain polyene status of preterm infants with regard to the fatty acid composition of their diet: comparison between absolute and relative fatty acid levels in plasma and erythrocyte phospholipids. British Journal of Nutrition 73, 405-422.

Holman, R. T. (1960). The ratio of trienoic: tetraenoic acids in tissue lipids as a measure of essential fatty acid requirement. Journal of Nutrition 70, 405-410.

Holman, R. T. (1977). The deficiency of essential fatty acids. In Polyunsaturated Fatty Acids, pp. 163-182 [W. Kunau and R. T. Holman, editors]. Champaign, IL: American Oil Chemists' Society.

Hornstra, G. (1992). Essential fatty acids, pregnancy and pregnancy complications. In Essential Fatty Acids and Eicosanoids, pp. 177-182 [A. Sinclair and R. Gibson, editors]. Champaign, IL: American Oil Chemists' Society.

Hornstra, G., Houwelingen, A. C. v., Simonis, M. \& Gerrard, J. (1989). Fatty acid composition of umbilical arteries and veins: possible implications for the fetal EFA status. Lipids 24, 511-517.

Houwelingen, A. C. v. (1988). Fish against thrombosis? Dietary fish and cardiovascular risk profile. PhD Thesis, Limburg University, Maastricht, The Netherlands.

Kaluzny, M. A., Duncan, L. A., Merritt, M. V. \& Epps, D. E. (1985). Rapid separation of lipid classes in high yield and purity using bonded phase columns. Journal of Lipid Research 26, 135-140.

Koletzko, B. \& Braun, M. (1991). Arachidonic acid and early human growth: is there a relation. Annals of Nutrition and Metabolism 35, 128-132.

Morissen, W. R. \& Smith, I. M. (1964). Preparation of fatty acid methyl esters and dimethyl acetates from lipids with boron fluoride methanol. Journal of Lipid Research 5, $600-608$.

Olsen, S. F., Dalby Sørensen, J., Secher, N. J., Hedegaard, M., Brink Hendriksen, T., Hansen, H. S. \& Grant, A. (1992). Randomized controlled trial of effect of fish-oil supplementation on pregnancy duration. Lancet 339 , 1003-1007.

Olsen, S. F., Hansen, H. S., Sorensen, T. I., Jensen, B., Secher, N. J., Sommer, S. \& Knudsen, L. B. (1986). Intake of marine fat, rich in ( $n-3)$-PUFA, may increase birthweight by prolonging gestation. Lancet ii, 367-369.

Popeski, D., Ebbeling, L. R., Brown, P. B., Hornstra, G. \& Gerrard, J. M. (1991). Blood pressure during pregnancy in Canadian Inuit : community differences related to diet. Canadian Medical Association Journal 145, 445-454.

Secher, N. J. \& Olsen, S. F. (1990). Fish oil and pre-eclampsia (commentary). British Journal of Obstetrics and Gynaecology 97, 1077-1079.

Sørensen, J. D., Olsen, S. F., Pedersen, A. K., Boris, J., Secher, N. J. \& FitzGerald, G. A. (1993). Effects of fish oil supplementation in the third trimester of pregnancy on prostacyclin and thromboxane production. American Journal of Gynecology 168, 915-922. 
Uauy, R., Birch, E., Birch, D. \& Peirano, P. (1992). Visual and brain function measurements in studies of $n-3$ fatty acid requirements of infants. Journal of Pediatrics 120, S168-S180.

Vilbergson, G., Samsioe, G., Wennergren, M. \& Karlsson, K. (1991). Essential fatty acids in pregnancies complicated by intrauterine growth retardation. International Journal of Gynecology and Obstetrics 36, $277-286$.

Wainwright, P. E. (1992). Do essential fatty acids play a role in brain and behavioral development? Neuroscience Biobehavior Review 16, 193-205.

Walsh, S. W. (1985). Pre-eclampsia; an imbalance in placental prostacyclin and thromboxane production. American Journal of Obstetrics and Gynecology 152, 335-350. 